\title{
FIELD STUDIES OF TEMPERATURE DISTRIBUTION IN A STRAW BUILDING WALL
}

\author{
Dainius RAMUKEVIČIUS, Department of Water Engineering, Faculty of Engineering, Vytautas MagnusUniversity, K. Donelaičio \\ g. 58, LT-44248 Kaunas, Lithuania, dainius.ramukevicius@vdu.lt (corresponding author) \\ Raimondas ŠADZEVIČIUS, Department of Water Engineering, Faculty of Engineering, Vytautas MagnusUniversity, K. Donelaičio \\ g. 58, LT-44248 Kaunas, Lithuania, raimundas.sadzevicius@vdu.lt \\ Rytis SKOMINAS, Department of Water Engineering, Faculty of Engineering, Vytautas Magnus University, K. Donelaičio g. 58, \\ 44248 Kaunas, Lithuania, rytis.skominas@ vdu.lt \\ Vincas GURSKIS, Department of Water Engineering, Faculty of Engineering, Vytautas Magnus University, K. Donelaičio g. 58, \\ 44248 Kaunas, Lithuania, vincas.gurskis@vdu.lt
}

It is proven that human construction activities affect the environment negatively. The threat of global ecological disaster is one of the most important factors, appearing due to unbalanced human activities and insufficient use of natural resources.

In Lithuania there are building materials (bricks, concrete, reinforced concrete and other materials) used for construction of buildings that require a lot of energy. Prices of energy grew up several times in recent years, so the prices of construction materials significantly increased.

It is suggested to use more local building materials produced with low energy consumption. The usage of local, renewable raw building materials can reduce $\mathrm{CO}_{2}$ emissions, ambient air pollution. The use of straw bales as construction material has many advantages. Pressed straw can be used as a natural heat insulating material in the construction of buildings in Lithuania, as it does not contradict the essential requirements of the construction of buildings specified in the Law on Construction and other normative documents. The aim of this study is to evaluate the temperature distribution of the wall of a built building made of straw bales during the cold period of the year. Temperature data loggers with thermocouple sensors were used to record the outdoor air, indoor and wall temperatures. Measurements of the temperature of the wall frame of the building filled with straw showed that the temperature field of the wall is in a constant dynamic state. It was found that the temperature of the individual layers of the walls of the building filled with straw varies tendentiously depending on the outdoor air temperature.

Keywords: straw, temperature, building wall, building materials

\section{INTRODUCTION}

There are local building materials in rural areas that could be used much more widely. Such materials include byproducts of crop production: straw, hemp, flax. In addition, local, agricultural, rural materials include hemp, flax fiber, sheep's wool, wood and wood processing waste, reeds, unburned clay, and natural stones. In the construction of warm buildings, renewable materials such as straw, sheep wool, hemp fiber, reeds could be used instead of the commonly used, but not environmentally friendly, heat-insulating building materials, such as stone wool, polystyrene foam. The processing of the latter into mats requires certain equipment and tools. This could be done by sheep and hemp farms in cooperation.

Straw as a building material has been known since the first steps of construction. They are used as a heat-insulating material and, when the production of pressed straw bales is started, as a sound-insulating and construction material (Ashour et al., 2011; Douzane, 2015). Construction from straw is classified as ecological, as the raw material is a byproduct of agricultural production, which requires very low energy consumption to produce (compress) and transport compared to traditional building materials (Costes et al., 2017; Mehmet et al., 2017; Bainbridge, 2000).

The use of straw as a building material is often associated with a certain distrust, fears: the building will burn, rot, it will be attacked by mice, rats. In Germany in 2006 the technical conditions for pressed straw used for construction were prepared by order of the construction from the Pressed Straw Union the Straw Construction Directive (Strohbaurichtlinie SBR-2014), and the straw certificate for construction (Algemeine bauaufsichtliche zulassung No. Z-23.11-1595), which sets out specific requirements for pressed straw bales. It is stated that the dimensions of pressed straw bales may not differ from those specified by more than $3 \%$. The dimensions shall be pressurized to $1 \mathrm{kPa}\left(100 \mathrm{~kg} / \mathrm{m}^{2}\right)$. The density of air-dried pressed straw, maintained at $50 \%$ relative humidity and $+23{ }^{\circ} \mathrm{C}$, must be $85-115 \mathrm{~kg} / \mathrm{m}^{3}$. The humidity after keeping the pressed straw at $80 \%$ relative humidity and $+23{ }^{\circ} \mathrm{C}$ must not exceed $18 \%$. It is noted that pressed straw in building

Copyright () 2021 The Authors. Published by Vytautas Magnus University. This is an open-access article distributed under the terms of the Creative Commons Attribution License (CC BY 4.0), which permits unrestricted use, distribution, and reproduction in any medium, provided the original author and source are credited. 
structures must be protected from precipitation, wind, moisture, ignition and other adverse factors by covering them with other materials resistant to these factors (Munch-Andersen, 2016). Exposed straw surfaces must be covered with plaster.

In recent years, the use of pressed straw has received a lot of attention in newspapers and magazines, and a lot of research has been done in this area. With the spread of press-insulated buildings in Lithuania, additional research is needed to assess the impact of various factors. The tests are usually performed under laboratory conditions (Baozhu et al., 2021). However, little research has been done on buildings with pressed straw on the walls. Therefore, the aim of the study is to evaluate the temperature distribution of the wall of a built building made of straw bales during the cold period of the year.

\section{MATERIALS AND TEST METHODS}

To determine the temperature regime of the building walls, a frame building was built - a model in which straw bales were used as thermal insulation material for the walls (Fig.1). The building area of the building is $11 \mathrm{~m}^{2}$. Wood is used for the wall frame pillars. The width of the straw bale is $40 \mathrm{~cm}$. Straw compression ratio not less than $100 \mathrm{~kg} / \mathrm{m}^{3}$. It is a wall with an effective layer of thermal insulation and a thermal resistance of about $5 \mathrm{~m}^{2} \mathrm{~K} / \mathrm{W}$. The interior walls of the building are plastered with a layer of clay, and the wall is not plastered at the temperature measurement site. Wood siding was used to decorate the exterior wall of the building. The doors of the building are made of wood. The windows have wooden frames and a hinged sash. Heat transfer coefficient of doors and windows $\mathrm{U}=1.6 \mathrm{~W} /\left(\mathrm{m}^{2} \mathrm{~K}\right)$. The roof of the building is made of wood chips. The building is equipped with a natural ventilation system. The roof is equipped with a ventilation chimney with adjustable air extraction, the doors are equipped with adjustable ventilation openings.

When choosing the temperature measurement location in the wall, the configuration of the building, the layout of windows and doors were taken into account and the possible influence of external factors was assessed. The temperature in the wall was measured in the transverse direction of the wall, in two places. Inside the wall, the temperature change is recorded at a distance of $10 \mathrm{~cm}$ from the outer and inner surfaces of the wall. Temperature data loggers with thermocouple sensors were used to record the outdoor air, indoor and wall temperatures. During the studies, data were collected every 4 hours. Natural temperature surveys were conducted in February, March and April. During the study period, the building was not heated, no heat sources were used. The study wall was oriented to the South.

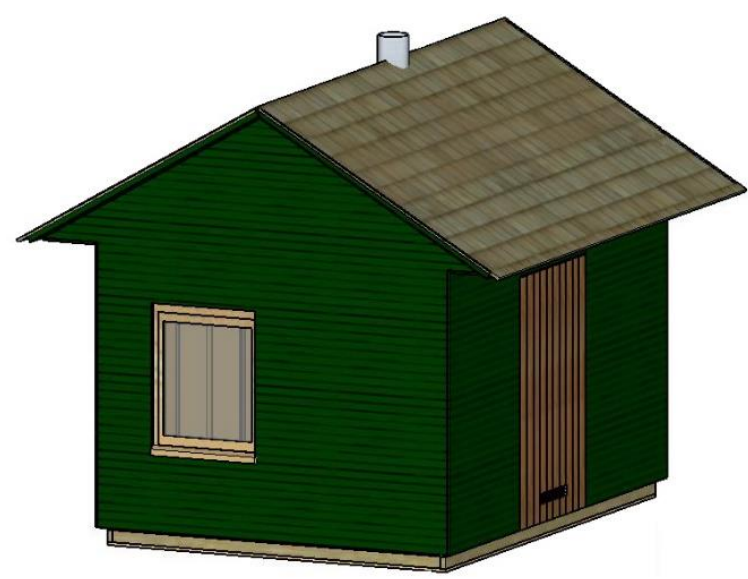

Figure 1. Building (model) with straw bale walls

\section{TEST RESULTS}

The external partitions of a building are homogeneous, we have two contact surfaces: outdoor air - partition, partition - indoor air, which determine the temperature distribution and heat transfer processes from the outside to the partition and its deep layers, and from them to the indoor dynamics.

Fluctuations in the wall temperature of the building had a seasonal nature, as the Lithuanian climate is characterized by changes in air temperature at different times of the year. From the graph of temperature change over time, it can be seen from Figure 2 that the highest measured indoor temperature of the building is $16.0^{\circ} \mathrm{C}$ in April, the lowest on some days is $0.5^{\circ} \mathrm{C}$. March and April stand out, where significant temperature fluctuations are observed.

The indoor air temperature of the building varies from 0.5 to $16^{\circ} \mathrm{C}$. During the study period, the highest monthly actual air temperature $\left(19.1^{\circ} \mathrm{C}\right)$ was found in April, and the lowest $\left(-5.3^{\circ} \mathrm{C}\right)$ in March. Outdoor air temperature indicators range from -5.3 to $19.1^{\circ} \mathrm{C}$.

The measurement results show that the indoor air temperature of the building, although very slightly above $0{ }^{\circ} \mathrm{C}$, remained positive throughout the study (the interior of the building is not heated). The change in the indoor temperature of the building was influenced by the direct change in the outdoor air temperature. The temperature change occurred through the building walls and ventilation. The temperature change occurred through the building's partitions and ventilation. 


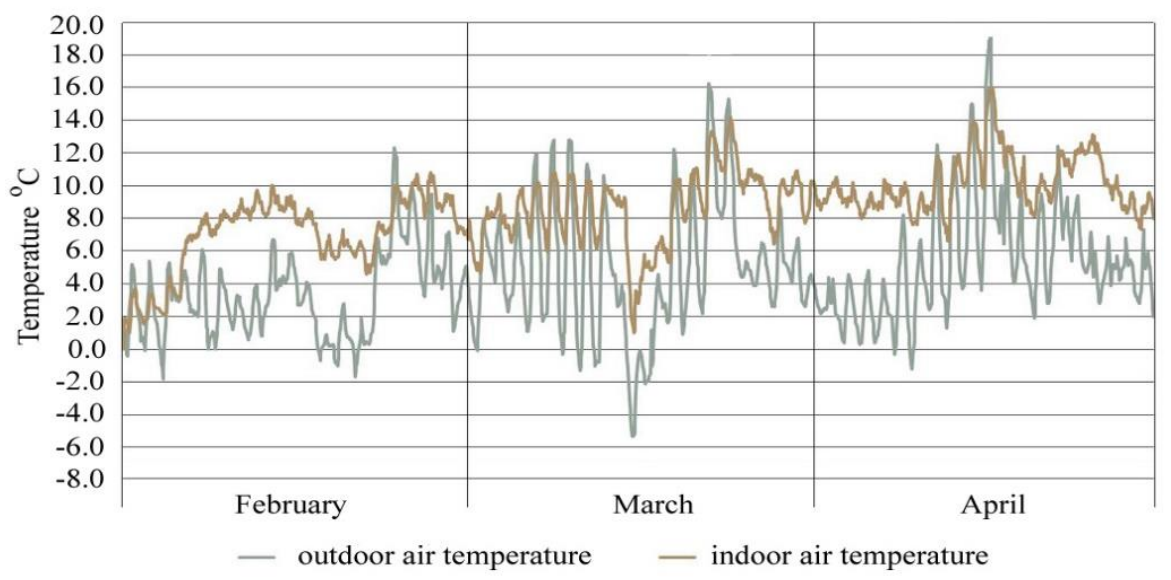

Figure 2. Comparison of outdoor - indoor temperatures

Typically, heat exchange and temperature fields in a building wall occur depending on changes in outdoor air parameters. Often these heat exchangers are treated as stationary. To determine the temperature distribution in the wall of the building, temperatures were recorded at two measurement points during the study. Two thermocouples were installed in the straw bundle layer of the outdoor wall of the building. One thermocouple was installed $10 \mathrm{~cm}$ from the surface of the outdoor layer, the other thermocouple was installed at a distance of $10 \mathrm{~cm}$ from the indoor wall surface. The measuring points are at a distance of $10 \mathrm{~cm}$ from the wall surfaces. The obtained measurement results are presented in Figures 3 and 4.

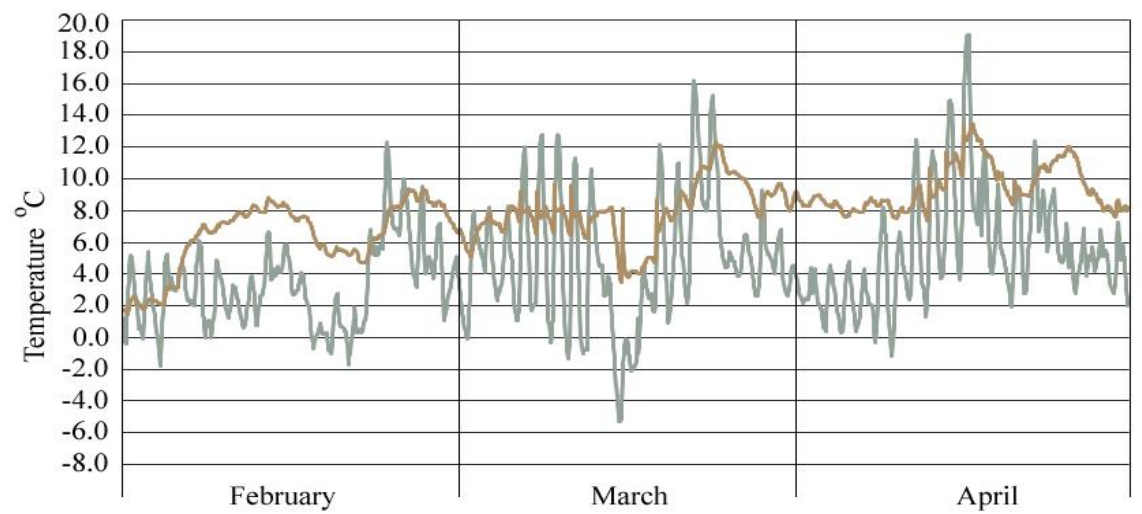

— oudoor air temperature _ wall temperature at a depth of $10 \mathrm{~cm}$

Figure 3. Comparison of outdoor - wall indoor $(10 \mathrm{~cm} \mathrm{depth)} \mathrm{temperatures}$

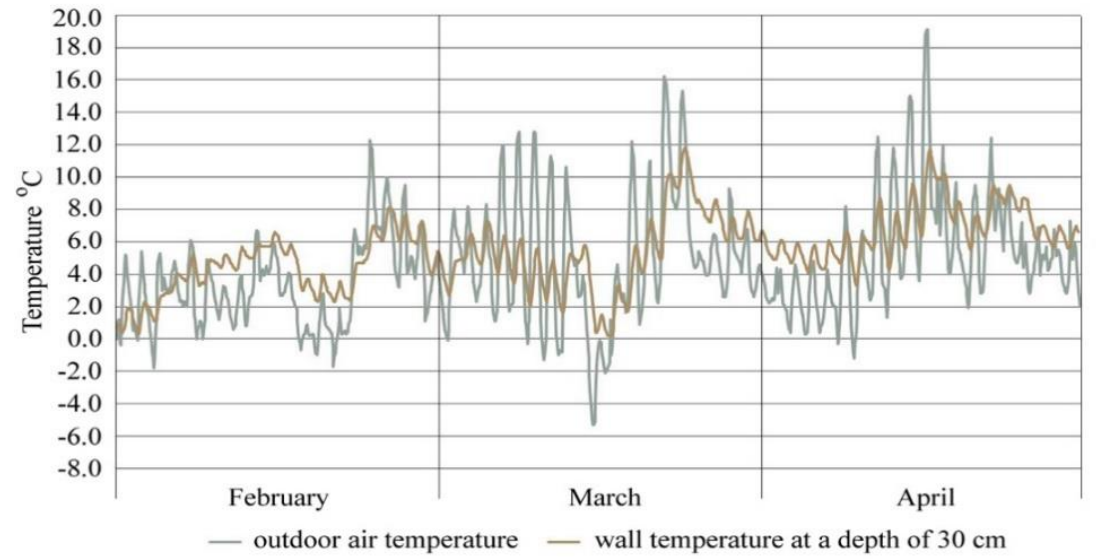

Figure 4. Comparison of outdoor - wall indoor (30 cm depth) temperatures

The data in the graphs show that on some days the temperature of the indoor layers of the wall exceeds the temperature of the outdoor air. This means that the heat flow inside the wall due to the influence of solar radiation changes its direction. This is confirmed by scientific studies, which show that even at relatively low intensities of solar radiation, it has a greater influence on the distribution of the temperature outside the wall than the outdoor air temperature. In the presence of solar radiation during the day, in the heat balance of the outdoor wall surface, the largest part consists of the 
energy provided by solar radiation, part of which enters the indoor layers of the wall by conductivity, part by long waves radiated to the environment and part by convection.

The graphs show that temperature fluctuations in the building wall are quite complex and have cyclical signs. The most pronounced temperature fluctuations were found closer to the outdoor wall surface at a distance of $10 \mathrm{~cm}$ from the outdoor wall surface (Fig. 3). Less pronounced, significantly lower amplitude temperature fluctuations were found at a distance of $10 \mathrm{~cm}$ from the indoor wall surface (Fig. 4). Heat exchange, judging by temperature changes, takes place throughout the wall layer.

From the data presented in Figure 3, it can be seen that the temperature fixed at a distance of $10 \mathrm{~cm}$ from the outdoor wall surface changes tendentiously between the outdoor air temperature throughout the study. Temperature fluctuations have a sudden rise and fall pattern. The temperature ranged practically from $0{ }^{\circ} \mathrm{C}$ to $11.8{ }^{\circ} \mathrm{C}$. The lowest temperatures were in February and March. On some days of these months, it was close to $0^{\circ} \mathrm{C}$. Such temperature indicators depend directly on the outdoor air temperature regime.

From the data presented in Figure 4, it can be seen that the temperature distribution inside the building wall at a distance of $10 \mathrm{~cm}$ from the indoor surface depends on the larger layer of straw $(30 \mathrm{~cm})$. No indoor wall trim was installed at the measurement site. The measurement results show that the temperature inside the building wall at a distance of 10 $\mathrm{cm}$ from the indoor surface varied from 1.8 to $13.6^{\circ} \mathrm{C}$. The average temperature was set at $6.4{ }^{\circ} \mathrm{C}$ in February, $7.2^{\circ} \mathrm{C}$ in March and $8.6^{\circ} \mathrm{C}$ in April. The lowest temperature was found at the beginning of the measurements, in February, when the average outdoor air temperature for this month was $3.7^{\circ} \mathrm{C}$.

The change in the temperature inside the wall of the building at a distance of $10 \mathrm{~cm}$ from the indoor surface compared to the outdoor air temperature is not so pronounced. The graph shows lower amplitude temperature fluctuations. There is no such sudden change in temperature when the outdoor temperature drops sharply. This temperature distribution is determined by the layer of straw, the decoration of the outdoor wall of the building and the accumulation of heat in the wall of the building.

\section{CONCLUSIONS}

Measurements of the temperature of the wall frame of the building filled with straw showed that the temperature field of the wall is in a constant dynamic state. The heat exchange between the outside and the inside of the building is conditioned by the outdoor temperature regime.

The dependence between the air temperature in the building and outdoors has been determined, where as the outdoor air temperature changes, so does the air temperature in the building. During the research, the outdoor air temperature varied from -5.3 to $19.1^{\circ} \mathrm{C}$, and the indoor air temperature of the building varied from 0.5 to $16^{\circ} \mathrm{C}$. The average daily temperature of the building was $9.8^{\circ} \mathrm{C}$ higher than outdoors.

It was found that the temperature of the individual layers of the walls of the building filled with straw varies tendentiously depending on the outdoor air temperature. The most pronounced temperature fluctuations were found at a distance of $10 \mathrm{~cm}$ from the outdoor wall surface.

\section{REFERENCES}

1. Ashour T., Georg H., Wu W. 2011. Performance of Straw Bale Wall: a Case of Study. Energy and Buildings, Vol. 43, pp. 19601967. https://doi.org/10.1016/j.enbuild.2011.04.001

2. Bainbridge D. A. 2000. Straw bales stack up for buildings. A lost art resurfaces in the modern world. Resource, Engineering \& Technology for a Sustainable World, Vol. 7, No 3.

3. Baozhu C., Jun H., Yuansong S., Hongxin N. 2021. Laboratory Investigations Into the Bearing Capacity of Straw Bales for LowRise Building Applications. Advances in Civil Engineering, Vol. 2021, Article ID 5557040, pp. 1-10 https://doi.org/10.1155/2021/5557040

4. Brzyski P., Kosiński P., Nadratowska M. 2019. Thermal Bridge Occurrence in Straw-Bale Timber Frame Walls. IOP Conference Series: Materials Science and Engineering, Vol. 710. https://doi.org/10.1088/1757-899X/710/1/012029

5. Costes J. P., Evrard A., Biot B., Keutgen G., Daras A., Dubois S., Lebeau F., Courard L. 2017. Thermal Conductivity of Straw Bales: Full Size Measurements Considering the Direction of the Heat Flow. Buildings, Vol. 7, pp. 1-15 https://doi.org/10.3390/buildings7010011.

6. Douzane O., Promis G., Roucoult J.-M., Tran Le A.-D., Langlet T. 2015. Hygrothermal Performance of a Straw Bale Building: in Situ and Laboratory Investigations. Journal of Building Engineering, Vol. 8, pp. 91-98. https://doi.org/10.1007/978-3-030-900557_22

7. Ghoreishi A. H., Mir A. M. 2012. Contribution of Thermal Mass to Energy Performance of Buidings: A Cormparative Analysis. International Journal of Sustainable Building Technology and Urban Development, Vol. 2(3), pp. $245-252$. https://doi.org/10.5390/SUSB.2011.2.3.245

8. Mehmet F. A., Ahmet E.T., Omer F.C. 2017. Strawbale Houses: a Quick Solution to Accomodation Problem. '3rd International Conference on Sustainable Construction Materials and Technologies. Available on: http://www.claisse.info/2013\%20papers/data/e024.pdf

9. Munch-Andersen J., Andersen B. M. 2016. Straw Bale Houses - Design and Material Properties. Danish Building and Urban Research, Statens Byggforskningsinstitutt. 